\title{
Teriflunomide Promotes Oligodendroglial 8,9-Unsaturated Sterol Accumulation and CNS Remyelination
}

\author{
Elodie Martin, PhD,* Marie-Stephane Aigrot, PhD, * Foudil Lamari, MD, PhD, Corinne Bachelin, PhD, \\ Catherine Lubetzki, MD, PhD, Brahim Nait Oumesmar, PhD, Bernard Zalc, MD, PhD, and \\ Bruno Stankoff, MD, PhD
}

Neurol Neuroimmunol Neuroinflamm 2021;8:e1091. doi:10.1212/NXI.0000000000001091

\section{Abstract}

\section{Background and Objectives}

To test whether low concentrations of teriflunomide (TF) could promote remyelination, we investigate the effect of TF on oligodendrocyte in culture and on remyelination in vivo in 2 demyelinating models.

\section{Methods}

The effect of TF on oligodendrocyte precursor cell (OPC) proliferation and differentiation was assessed in vitro in glial cultures derived from neonatal mice and confirmed on fluorescenceactivated cell sorting-sorted adult OPCs. The levels of the 8,9-unsaturated sterols lanosterol and zymosterol were quantified in TF- and sham-treated cultures. In vivo, TF was administered orally, and remyelination was assessed both in myelin basic protein-GFP-nitroreductase ( $M b p$ : GFP-NTR) transgenic Xenopus laevis demyelinated by metronidazole and in adult mice demyelinated by lysolecithin.

\section{Results}

In cultures, low concentrations of TF down to $10 \mathrm{nM}$ decreased OPC proliferation and increased their differentiation, an effect that was also detected on adult OPCs. Oligodendrocyte differentiation induced by TF was abrogated by the oxidosqualene cyclase inhibitor Ro 48-8071 and was mediated by the accumulation of zymosterol. In the demyelinated tadpole, TF enhanced the regeneration of mature oligodendrocytes up to 2.5 -fold. In the mouse demyelinated spinal cord, TF promoted the differentiation of newly generated oligodendrocytes by a factor of 1.7-fold and significantly increased remyelination.

\section{Discussion}

TF enhances zymosterol accumulation in oligodendrocytes and CNS myelin repair, a beneficial off-target effect that should be investigated in patients with multiple sclerosis.
Correspondence

Dr. Stankoff

bruno.stankoff@aphp.fr

*These authors contributed equally to this work.

From the Sorbonne Université, Paris Brain Institute, CNRS, Inserm (E.M., M.-S.A., C.B., C.L., B.N.O., B.Z., B.S.); Pitié-Salpêtrière Hospital, APHP (F.L., C.L.); and Saint Antoine Hospital, APHP (B.S.), Paris, France. 


\section{Glossary}

ANOVA $=$ analysis of variance; $\mathbf{A P C}=$ adenomatous polyposis coli; $\mathbf{B B B}=$ blood brain barrier; $\mathbf{B r}=$ brain; $\mathbf{B r d U}=$ bromodeoxyuridine; DHODH = dihydroorotate dehydrogenase; DIV = days in vitro; EBP = emopamil binding protein; FACS = fluorescence-activated cell sorting; IFN $\gamma=$ interferon-gamma; IL-17 = interleukin-17; Li = liver; LPC = lysophosphatidylcholine; MBP = myelin basic protein; Mbp:GFP-NTR = myelin basic protein-GFP-nitroreductase; MOG = myelin oligodendrocyte glycoprotein; $\mathbf{M S}=$ multiple sclerosis; $\mathbf{M T T}=$ 3-(4,5-dimethylthiazol-2-yl)-2,5-diphenyltetrazolium bromide; MTZ = metronidazole; $\mathbf{O P C}=$ oligodendrocyte precursor cell; PBS = phosphate-buffered saline; PDGFa::GFP = platelet derived growth factor receptor-alpha/green fluorescent protein; $\mathbf{P F A}=$ paraformaldehyde; $\mathbf{S C}=\operatorname{spinal}$ cord; $\mathbf{S p}=$ spleen; $\mathbf{T F}=$ teriflunomide.

The landscape of multiple sclerosis (MS) treatment has changed dramatically over the last decades, with great therapeutic progresses achieved for the prevention of clinical relapses. However, controlling the disability worsening remains a key unsolved issue, as currently applied therapeutic strategies targeting the adaptive immune system are mostly insufficient to prevent later disability accrual and disease progression. Disability in MS is mainly a consequence of irreversible neuronal damage that could be induced jointly by chronic inflammation and persisting demyelination. ${ }^{1,2}$ Following a demyelinating insult, an endogenous spontaneous repair process may take place to prevent the deleterious consequences of demyelination and protect axons from degeneration. ${ }^{3,4}$ Whereas some remyelination may occur in $\mathrm{MS}^{5-7}$ this regenerative process is often abortive and generally insufficient to fully repair lesion and prevent neurodegeneration. ${ }^{8}$ Beside immunomodulation, a major therapeutic goal aiming at promoting remyelination has therefore emerged. From in vitro and in vivo experimental models, a certain number of either repurposed or newly designed molecules have been identified as promising remyelinating compounds. ${ }^{8}$ Of interest, most of these molecules were shown to promote oligodendrocyte differentiation and (re)myelination independently of their canonical targets through the accumulation of 8,9-unsaturated sterols in myelinating cells. ${ }^{9}$ Whether some currently approved drugs targeting the adaptive and/or innate immunity could also exert a promyelinating effect through off-target mechanisms remain poorly investigated, but would open the perspective of a dual beneficial impact on MS course.

Teriflunomide (TF) is an oral immunomodulatory therapy that has been approved for relapsing-remitting forms of MS. ${ }^{10}$ Its primary mechanism of action is an inhibition of dihydroorotate dehydrogenase (DHODH), a mitochondrial enzyme involved in pyrimidine synthesis pathway highly expressed in proliferating lymphocytes. ${ }^{11}$ Beyond its impact on lymphocytes, it has been suggested that TF could promote oligodendrocyte differentiation in primary cultures from immature rat brains. ${ }^{12}$ However, this effect was observed only for very short pulses on immature cells, disappeared when administration was prolonged for several days, and was observed only for a single concentration of $5 \mu \mathrm{M}$, which corresponds approximately to the one to be found in the blood, but that could hardly be reached in the brain of human treated subjects. These results are therefore difficult to translate to human care, prompting us to explore more in depth the potential impact of this drug on myelinating cells and remyelination.

Combining a range of in vitro and in vivo models from different species, we have obtained results supporting a promyelinating effect of TF: (1) at nanomolar concentrations, TF promotes the differentiation of neonatal and adult mouse oligodendrocytes; (2) its effect on oligodendrocyte was associated with an accumulation of the 8,9-unsaturated sterol zymosterol and reverted by inhibition of the oxidosqualene cyclase; and (3) TF promoted remyelination in vivo both in Xenopus laevis and in mice.

\section{Methods}

\section{Animals}

All animal experiments were conducted with respect to the European Union regulations and approved by the ethical committee for animal use (approval number Ce5/2010/025) (APAFIS \#6269 and APAFIS \#5842-2016101312021965).

\section{Mice}

C57/Bl6 and transgenic PDGFRa:GFP (reference 13; RRID: IMSR_JAX:007669) mice were grown in our animal facility (agreement \#A75-13-19). Experiments were conducted with respect to the European Union regulations and approved by the ethical committee for animal use (approval number Ce5/ 2010/025) (APAFIS \#6269).

\section{Xenopus}

In the myelin basic protein-GFP-nitroreductase (Mbp:GFPNTR) transgenic Xenopus laevis line, the expression of the green fluorescent protein GFP reporter gene and the bacterial NTR enzyme is controlled by a portion of the mouse myelin basic protein (MBP) regulatory sequence, ${ }^{14}$ enabling a selective expression of the transgene in myelinating oligodendrocytes and the induction of oligodendrocyte death and demyelination when metronidazole (MTZ) is added to the swimming water. ${ }^{15}$ In this model, remyelination (spontaneous or induced by TF) can be assessed following a recovery period of 3 days. Treatment was performed at a pre-metamorphosis stage. ${ }^{16}$

\section{Cell Cultures and Treatment}

Oligodendrocyte precursor cells (OPCs) were isolated from neonatal mice (P1 or P2) using a Percoll gradient. ${ }^{17}$ OPCs were 
isolated from 2-month-old adult platelet derived growth factor receptor-alpha/green fluorescent protein ( $P D G F a: G F P)$ hemizygous mice $^{18,19}$ through $\mathrm{GFP}^{+} / \mathrm{O}^{+}$fluorescence-activated cell sorting (FACS).

At days in vitro (DIV) 3, teriflunomide (Genzyme) at concentrations ranging from $10 \mathrm{nM}$ to $5 \mu \mathrm{M}$ was added, and cells were grown for 24,48 , and 96 hours to assess the survival, proliferation, and differentiation, respectively. OPCs were either untreated or treated with $10 \mathrm{nM}$ Ro 48-8071 fumarate (Tocris; an inhibitor of lanosterol synthesis), $25 \mu \mathrm{M}$ uridine (Sigma-Aldrich), rat recombinant interferon-gamma (IFN $\gamma)(10 \mathrm{ng} / \mathrm{mL} ;$ PeproTech), and/or rat recombinant interleukin-17 (IL-17) (50 ng/mL; R\&D Systems), either alone or in combination with $10 \mathrm{nM}$ TF for 96 hours.

\section{Cell Survival Assay}

Cell survival was measured by the 3-(4,5-dimethylthiazol-2-yl)2,5-diphenyltetrazolium bromide (MTT) rapid colorimetric assay $\left(0.5 \mathrm{mg} / \mathrm{mL} \mathrm{MTT}\right.$ incubated at $37^{\circ} \mathrm{C}$ with $5 \% \mathrm{CO}_{2}$ for 4 hours; Sigma-Aldrich, M5655). ${ }^{20}$

\section{Sterol Analysis}

OPCs were grown on poly-L-lysine-coated $100 \mathrm{~mm}^{2}$ Petri dish and at DIV 3, either TF (10 nM) or/and Ro 48-8071 fumarate $(10 \mathrm{nM})$ or/and uridine $(25 \mu \mathrm{M})$ were added during 24 hours. Cells were dissociated using 0.5\% trypsin/ ethylenediaminetetraacetic acid, scraped, and centrifuged 10 minutes at $10,000 \mathrm{rpm}$, and the supernatant was frozen at $-80^{\circ} \mathrm{C}$.

Sterol extraction and derivatization were performed as described. ${ }^{21}$ Briefly, $20 \mu \mathrm{L}$ of a mixture of deuterated sterols (Avanti Polar Lipids: Coger-Paris 15), consisting of (d5zymosterol $[1 \mu \mathrm{g} / \mathrm{mL}]$, d7-cholesterol $[10 \mu \mathrm{g} / \mathrm{mL}]$, and d6lanosterol $[1 \mu \mathrm{g} / \mathrm{mL}])$ in methanol as internal standards was added to $100 \mu \mathrm{L}$ of cell lysates. Following extraction in $n$ hexane, the dried residue of free sterols was derivatized, dissolved in methanol, and injected into the ultra performance liquid chromatography coupled with mass spectroscopy/MS system, consisting in a Triple Quadrupole Mass Spectrometer (TQD-Waters) equipped with an electrospray ionization probe and coupled to an ultra performance liquid chromatography Acquity system (Waters). ${ }^{22}$ A calibration curve was obtained by a mixture of zymosterol, lanosterol $(0.25 \mu \mathrm{g} / \mathrm{mL}$ each), and cholesterol $(50 \mu \mathrm{g} / \mathrm{mL})$. Sterol levels were normalized to protein concentration (bicinchoninic acid assay).

\section{Emopamil Binding Protein and DHODH Reverse Transcriptase-Quantitative Polymerase Chain Reaction}

OPCs and mouse tissue (brain, spinal cord [SC], spleen, and liver) messenger RNAs were isolated with the Maxwell RSC simplyRNA Cells (Promega). Primers for emopamil binding protein (EBP) (forward primer: TGTGCGAGGAGGAAGAAGAT; reverse primer: GATAGGCCACCCCGTTTATT) and DHODH (forward primer: TCCAATGGGATGCAGGCAG; reverse primer: CAGGGCCCGCTTTCTCAG) and glyceraldehyde 3-phosphate dehydrogenase (forward primer:
GGGTTCCTATAAATACGGACTGC; reverse primer: CCATTTTGTCTACGGGACGA) were designed by NCBI Primer-BLAST and manufactured by Eurofins Genomics. A LightCycler 480 SYBR Green I Master (Roche Diagnostics) was used for quantitative real-time PCR. The cycle time was calculated using LightCycler 96 Software V1.1.

\section{Antibodies}

Anti-O4 antibody (mouse IgM hybridoma provided by I. Sommer) was revealed by a phycoerythrin anti-mouse IgM (BD Pharmingen). For cell immunostainings, we used a rabbit antiOlig2 Ab (diluted 1:500, Millipore, AB15328), a mouse antimyelin oligodendrocyte glycoprotein (MOG) Ab (diluted 1:5, hybridoma provided by Dr. C. Linington), a mouse IgG1 anti$\mathrm{Ki}-67 \mathrm{Ab}$ (diluted 1:100, BD Biosciences-Pharmingen), and a rat anti-bromodeoxyuridine (anti-BrdU) (diluted 1:20, Abcam).

For immunohistochemistry, we used a chicken anti-MBP Ab (diluted 1:40, Millipore), a rabbit anti-Olig2 Ab (diluted 1: 500, Millipore, AB15328), and a mouse IgG2b antiadenomatous polyposis coli (APC, clone CC1; diluted 1:300, Calbiochem). Secondary antibodies used were Alexa conjugated antibodies (Invitrogen) at a 1:1,000 dilution.

\section{Immunofluorescence}

Cells were fixed 15 minutes with $4 \%$ paraformaldehyde (PFA) and permeabilized 10 minutes by $0.1 \%$ Triton-phosphatebuffered saline (PBS). For BrdU immunocytochemistry, fixed cells were incubated 10 minutes in $1 \mathrm{M} \mathrm{HCl}$-PBS on ice and 10 minutes in $2 \mathrm{M} \mathrm{HCl}-\mathrm{PBS}$ at room temperature before applying anti-BrdU antibody overnight at $+4^{\circ} \mathrm{C}$.

\section{Demyelinating Lesion Induction}

Focal demyelination was induced by an injection of $0.5 \mathrm{~mL}$ of 1\% LPC (lysophosphatidylcholine; Sigma-Aldrich, St Louis, $\mathrm{MO}$ ) in the dorsal SC of 2-month-old anesthetized PLP-GFP transgenic mice as described. ${ }^{23}$

\section{Oral Treatment}

Mice received $20 \mathrm{mg} / \mathrm{kg}$ of TF dissolved in dimethylsulfoxyde and resuspended in a solution containing $0.6 \%$ carboxymethylcellulose through oral gavage daily. An equivalent volume of identical vehicle solution without TF was given to control mice. Daily administration began the day following LPC injection and was repeated for 10 days.

\section{Perfusion and Tissue Processing for Immunohistochemistry}

The spinal cords of animals perfused with 4\% PFA (Sigma) were cryoprotected in $15 \%$ sucrose, frozen in $15 \%$ sucrose$7 \%$ gelatin and $14-\mu \mathrm{m}$ serial cryostat sections were performed. Immunohistochemistry was then realized according to the already reported procedure. ${ }^{23}$

\section{Tissue Processing for Electron Microscopy}

Mice were perfused with $2 \%$ PFA and $4 \%$ glutaraldehyde (Electron Microscopy Sciences, Hatfield, PA), and their SCs 
were postfixed overnight. Tissue was then processed as described. $^{23}$ One- $\mu \mathrm{m}$-thick sections were stained with toluidine blue, and ultrathin 70-nm sections (ultramicrotome; Reichert UltraCut S) were stained with uranyl acetate and Reynold lead citrate and observed with a transmission electron microscope (Hitachi, Tokyo, Japan).

\section{Image Acquisition and Quantitative Analysis}

For cell immunocytochemistry, a Zeiss Axio Imager Apotome was used. Ten fields captured from each well, corresponding to approximately $80-100$ Olig2 ${ }^{+}$cells per coverslip, were counted, and the percentage of myelin-forming oligodendrocyte $\left(\mathrm{Olig} 2^{+} / \mathrm{MOG}^{+}\right.$) cells was determined for at least 4 coverslips per condition.

For biochemistry experiments, each sample was measured in duplicate per condition, and sterol production was normalized to protein concentration evaluated by bicinchoninic acid assay. Results were expressed as \% of controls \pm SEM of 3 independent experiments.

For experiments in live tadpoles, the number of cells expressing GFP cells was quantified in each optic nerve ${ }^{24}$ using a Macroscope Nikon AZ100 with a $\times 15$ magnification. Data were obtained from 5 to 8 animals per condition.

For histology, we used a digital camera (AxioCam; Zeiss, Jena, Germany) attached to a microscope (Apotome; Zeiss) and performed Z-series of sections at $0.3-\mu \mathrm{m}$ increment. Green, red, far-red, and blue fluorescence were acquired sequentially. Five to 10 sections were analyzed per animal, and for every single image, the extent of myelin loss (characterized by a lack of MBP staining) was quantified using Zen software. Inside the lesion area/lesion core, the number of Olig2 ${ }^{+} \mathrm{CC}^{+}$cells was assessed.

For electron microscopy, a mean of 25 images per animal were analyzed within the lesion using a transmission electron microscope (Hitachi, Tokyo, Japan) connected to a digital camera (AMT, Danvers, MA) at $\times 13,000$. The number of remyelinated axons was counted (ImageJ software).

\section{Statistical Analysis}

Data are expressed as mean \pm SEM. Statistics were performed using GraphPad Prism 6 (GraphPad Software). For statistical differences between 2 groups, the unpaired 2 -tailed Student $t$ test was applied. For grouped analysis, we used a 1-way analysis of variance (ANOVA) followed by the Dunn post hoc test to compare drug treatment to control condition or Newman-Keuls test for multiple comparison. Statistical significance was defined as ${ }^{*} p<0.05,{ }^{* *} p<0.01$, and ${ }^{* * *} p<0.001$.

\section{Data Availability}

The data that support the findings of this study are available from the corresponding author on reasonable request.

\section{Results}

\section{TF Inhibits OPC Proliferation}

In newborn glial cultures, Olig-2 and 4',6-diamidino-2-phenylindole colabeling showed an $80 \%$ enrichment in OPCs (Figure 1, A and B). Compared with untreated control, addition of TF ( $10 \mathrm{nM}$ and $5 \mu \mathrm{M})$ in the culture medium for 24 hours did not affect cell viability of OPCs (Figure 1C). TF added 48 hours to the culture medium decreased OPC proliferation, measured as the incorporation of bromodeoxyuridine (BrDU), by $34 \%$ up to $63 \%$ for concentration ranging between $10 \mathrm{nM}$ and $5 \mu \mathrm{M}$, respectively (Figure 1, D-F). This effect for the lower $10 \mathrm{nM}$ concentration was further confirmed by quantifying the expression of the proliferation marker Ki67 (Figure 1, G-I).

\section{TF Increases Oligodendrocyte Differentiation}

We then asked whether the TF could influence OPC differentiation into mature oligodendrocytes. One of the most belated markers of oligodendrocyte maturation is myelin oligodendrocyte glycoprotein (MOG) ${ }^{25,26}$ In a first set of experiments, a 96-hour treatment of cultures with TF induced an increase in the ratio of mature oligodendrocytes (Olig2 ${ }^{+}$/ $\mathrm{MOG}^{+}$cells) by factors of 1.4 up to 2.1 for concentrations ranging from $10 \mathrm{nM}$ to $1 \mu \mathrm{M}$, respectively (Figure $2, \mathrm{~A}-\mathrm{C}$ ). This acceleration of maturation was also efficient on adult OPC FACS isolated from the brain of 2-month-old PDGFRa::GFP mice. In these cultures of adult OPCs, the low dose of TF (10 $\mathrm{nM}$ ) was sufficient to increase maturation (Figure 2, D-F).

\section{TF Promotes OPC Differentiation by Acting on the 8,9-Unsaturated Sterol Biosynthesis \\ Pathway}

In newborn OPC cultures, $10 \mathrm{nM}$ TF significantly increased OPC differentiation by a factor of 1.97 -fold in comparison to control ( $1.97 \pm 0.16$; TF vs $1 \pm 0.15$; Ctrl $)$. Cotreatment with Ro 48-8071, an inhibitor of lanosterol synthesis, abrogated the enhanced TF-induced oligodendroglial differentiation ( $1 \pm$ 0.15 of Olig2 ${ }^{+} \mathrm{Mog}^{+}$cells in TF-treated OPCs; $0.94 \pm 0.18$ of Olig2 ${ }^{+} \mathrm{Mog}^{+}$cells in OPCs cotreated with TF and Ro488071) (Figure 3A).

To investigate the mechanism involved in TF-induced OPC differentiation, we analyzed the levels of sterols produced by purified newborn OPCs. Cells were treated for 24 hours either with TF (10 nM) or Ro 48-8071 (10 nM) or cotreated with TF and Ro 48-8071. Three sterols along the cholesterol biosynthesis pathway were quantified: lanosterol (that accumulates following CYP51 inhibition), zymosterol, and cholesterol. Although TF did not significantly enhance lanosterol or cholesterol production, the zymosterol level was increased 1.9-fold in comparison to control. Addition of Ro 48-8071 effectively blocked TF-induced zymosterol production (Figure 3B).

Together, these findings indicate that the accumulation of the 8,9-unsaturated sterol zymosterol in OPCs is a crucial mechanism for TF-induced oligodendrocyte differentiation. A 


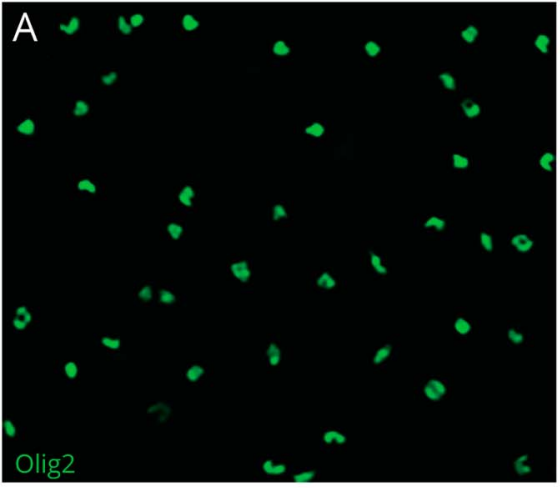

Control
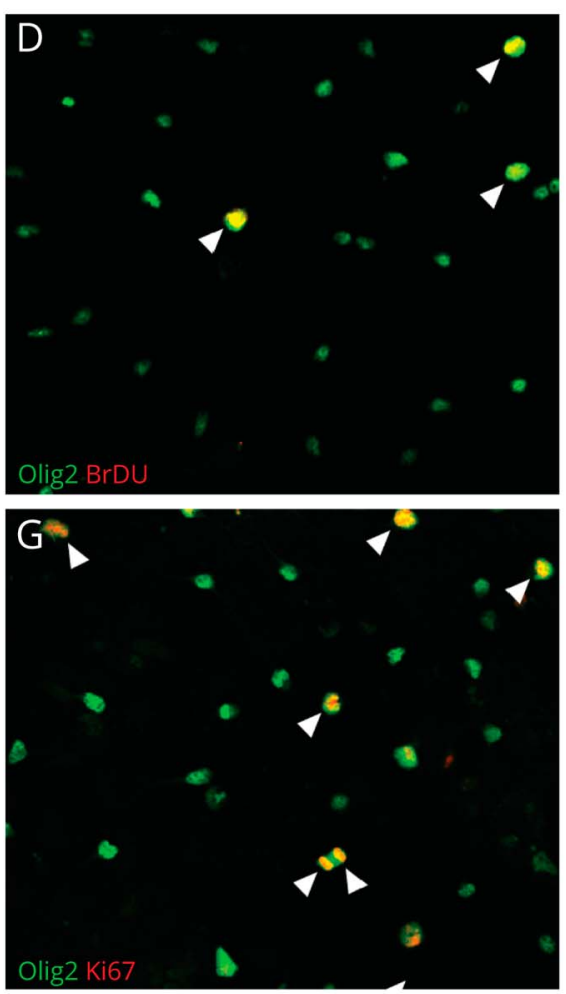

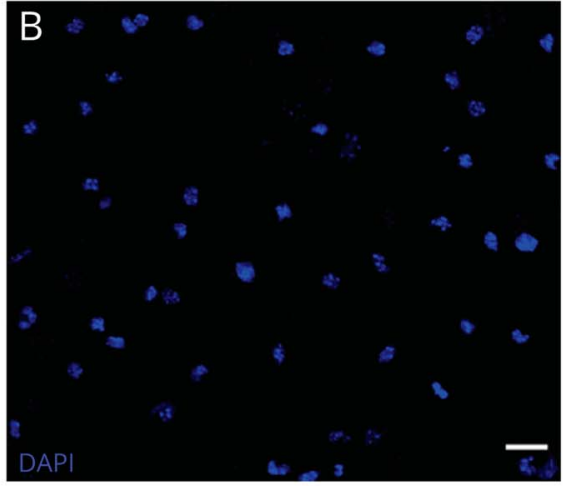

Teriflunomide
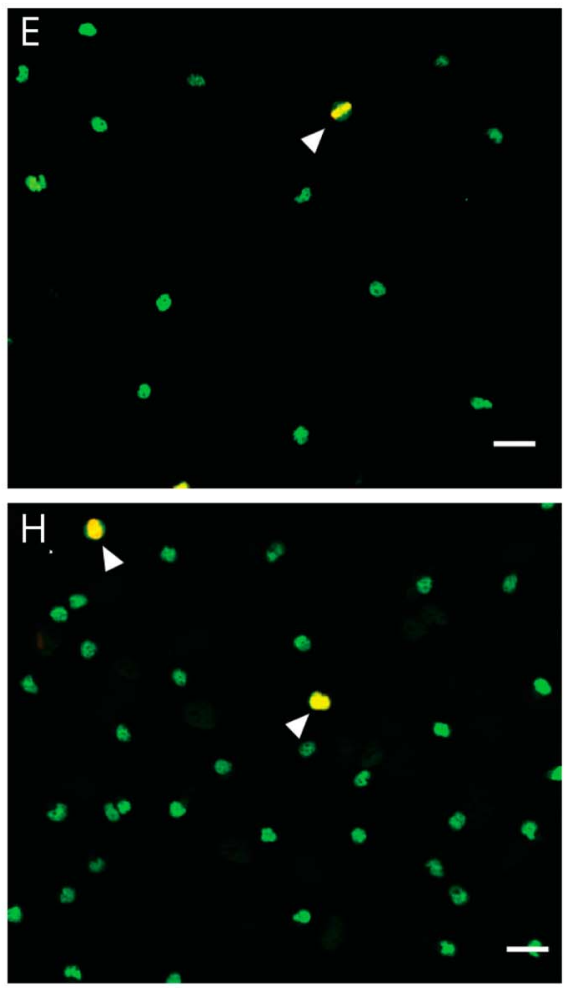

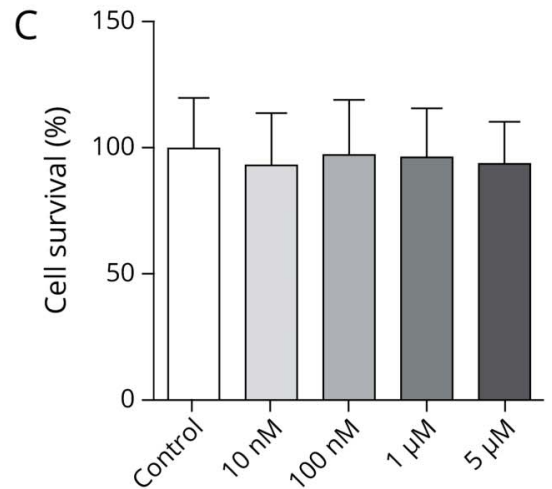

F
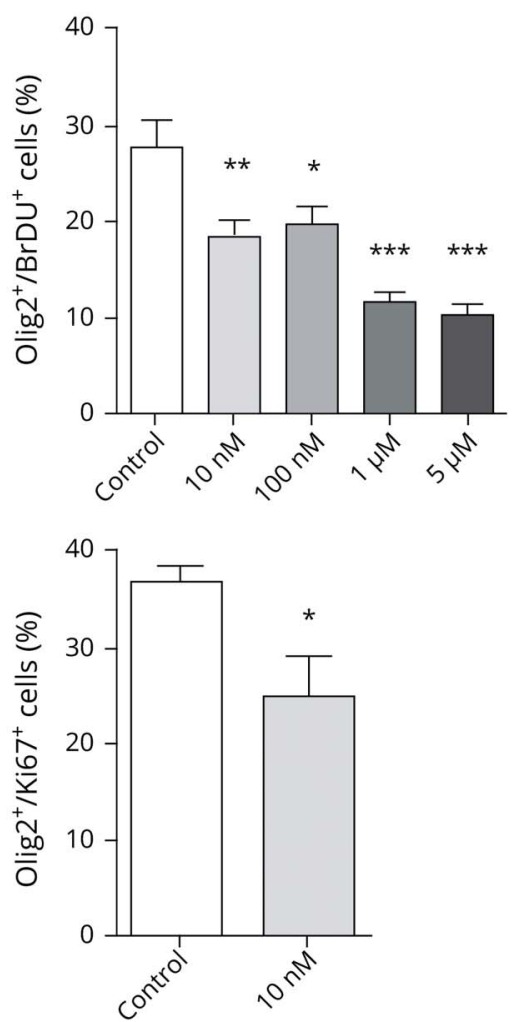

(A-C) Immunolabeling for Olig2 (A) and nuclei staining with 4',6-diamidino-2-phenylindole (B) showing that $80 \%$ of cells are Olig2 ${ }^{+}$cells. (C) Cell survival was evaluated with MTT assay: results are expressed as \% of controls and show that TF does not induce cell death at concentrations ranging between $10 \mathrm{nM}$ and $5 \mu \mathrm{M}$. (D and E) Coimmunolabeling for Olig2 and BrDU in control (Ctrl)- (D) and TF-treated conditions (E). (F) Cell proliferation was measured as the proportion of Olig2 $2^{+}$cells that are also BrDU ${ }^{+}$.TF decreased the percentage of Olig2 $2^{+}$cells coexpressing BrDU for concentrations ranging between $10 \mathrm{nM}$ and $5 \mu \mathrm{M}$. ( $\mathrm{G}$ and H) Coimmunolabeling for Olig2 and Ki67 in control (Ctrl)- (G) and TF-treated conditions (H). (I) The proportion of Olig2+ cells coexpressing Ki67 was lower in the teriflunomide condition $(10 \mathrm{nM})$ compared with control. White arrowheads indicate cells coexpressing the 2 markers. Data shown are mean \pm SEM from 3 to 5 individual experiments. ${ }^{*} p<0.05$; ${ }^{*} p<0.01 ;{ }^{*} * * p 0.001$ (1-way ANOVA, Dunn post hoc test $(\mathrm{C}$ and $\mathrm{F}$ ); Student 2-tailed unpaired $t$ test $(\mathrm{I})$ ). Scale bar in A-F = $10 \mu \mathrm{m} . \mathrm{BrdU}=$ bromodeoxyuridine; $\mathrm{TF}=$ teriflunomide .

similar accumulation of zymosterol has been previously reported with other enhancers of myelination such as clemastine $^{9}$ and may suggest that TF, which canonical signaling pathway targets the $\mathrm{DHODH}$, could also inhibit EBP, the enzyme catalyzing zymosterol in the cholesterol biosynthesis pathway.

This led us to analyze the expression of EBP and DHODH in OPCs and the brain and spinal cord from adult wild type mice.
We observed a moderate level of expression of both EBP and $\mathrm{DHODH}$ in OPCs relatively to the liver and spleen that were used as positive control for EBP and DHODH enzymatic gene expression, respectively, but this OPC expression was enriched compared with the brain or SC (Figure 3, C and D).

Whereas we could not demonstrate a direct interaction between TF and EBP in a specific screening assay (supplemental data, links.lww.com/NXI/A606), we showed that an excess of 

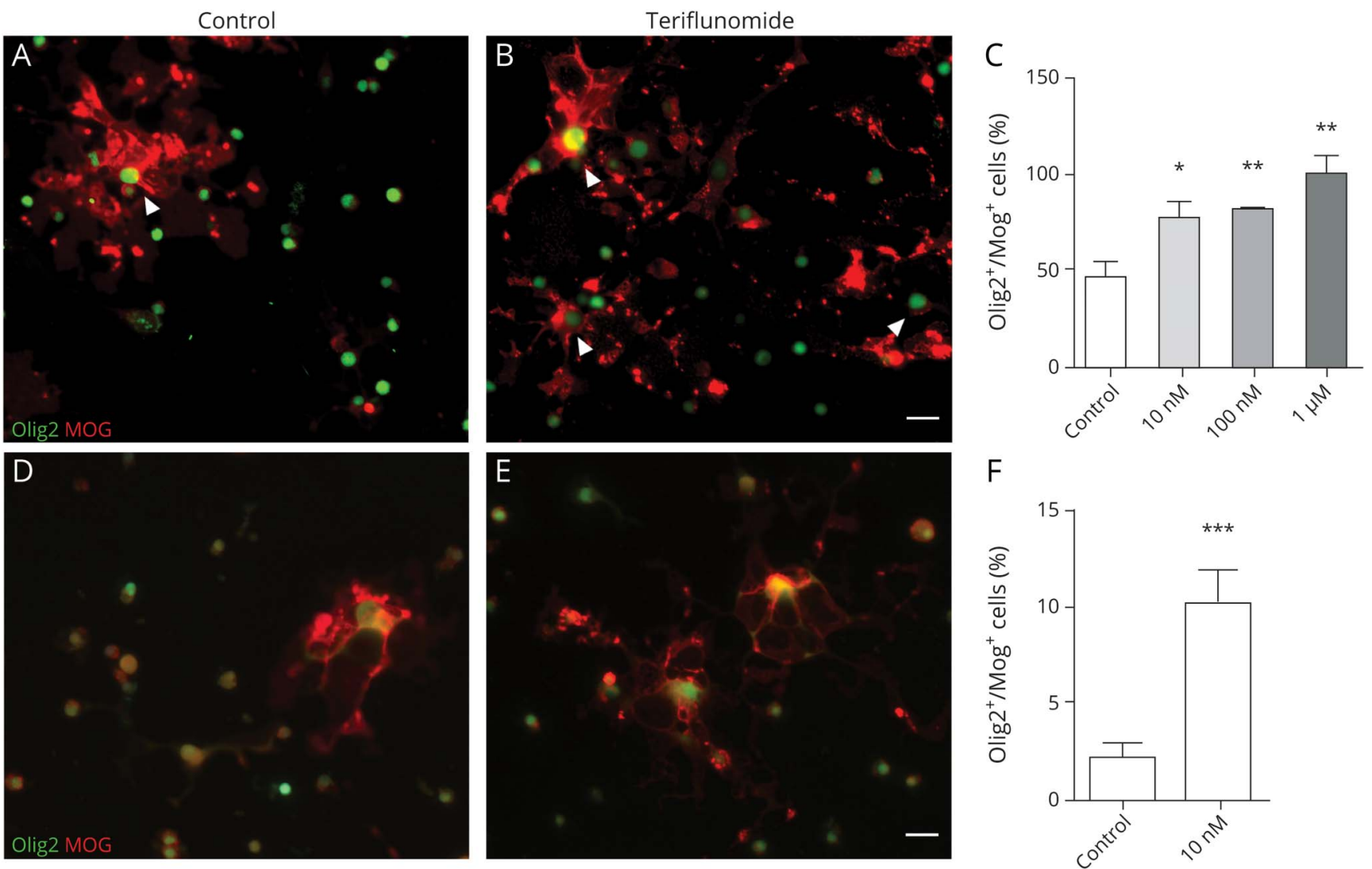

(A and B) Newborn-derived OPCs cultures fixed at DIV 7. Coimmunolabeling for Olig2 and MOG in control (Ctrl)- (A) and TF-treated conditions (B). White arrowheads indicate cells coexpressing Olig2 and MOG. (C) A higher proportion of Olig2+ cells were coexpressing MOG when treated with TF (10 nM-1 $\mu \mathrm{M})$ compared with the control condition. (D and E) Adult OPCs were isolated by fluorescence-activated cell sorting from the CNS of 2 months old PDGFRa:GFP mice and immunostained for Olig2 and MOG in control (Ctrl)- (D) and TF-treated conditions (E). (F) The percentage of Olig2 ${ }^{+}$cells coexpressing MOG is significantly increased in cultures treated with TF compared to control. Data shown are mean \pm SEM from 3 to 5 individual experiments. $* p<0.05 ; * \star p<0.01 ;$ $\star_{* \star} p<0.001$ (1-way ANOVA, Dunn post hoc test (C); Student 2-tailed unpaired $t$ test [F]). Scale bar in A-F=10 $\mu \mathrm{m}$. MOG = myelin oligodendrocyte glycoprotein; $\mathrm{OPC}=$ oligodendrocyte precursor cell; TF = teriflunomide.

uridine, that had no effect on OPC differentiation when added alone, could reverse the differentiation induced by TF treatment (Figure 3E). In addition, uridine totally blocked the accumulation of zymosterol induced by TF (Figure 3F).

Finally, adding recombinant cytokines to mimic the MS inflammatory environment, ${ }^{27}$ we found that a combined IFN $\gamma /$ IL-17 cytokine stimulation slightly decreased the OPC differentiation in comparison to control $(0.6 \pm 0.1 ; \mathrm{IFN} \gamma / \mathrm{IL}-17$ vs $1 \pm 0.1$; Ctrl) and that cotreatment with cytokines and TF reversed the differentiation induced by TF treatment $(1.1 \pm$ 0.2; TF + IFN $\gamma / \mathrm{IL}-17$ vs; $3.2 \pm 0.4$; TF).

\section{TF Treatment Increased Oligodendrocyte Remyelination in Vivo}

\section{In Xenopus laevis}

Mbp:GFP-NTR transgenic Xenopus laevis tadpoles were demyelinated with MTZ (10 mM) for 10 days (Figure 4, A and B) and then returned to either fresh water (controls) or water containing increasing concentrations of TF. After 10 days of exposure to MTZ, the number of $\mathrm{GFP}^{+}$cells per optic nerve significantly decreased from $24.75 \pm 4.5$ to $3.6 \pm 1.1$. Three days (R3) after withdrawal of MTZ, spontaneous recovery occurred, and oligodendrocytes per optic nerve reached $8.0 \pm 1.1$. Treatment of demyelinated tadpoles with TF improved remyelination by a factor of 1.5-, 1.8-, and 2.25-fold for concentrations of 1, 10, and $100 \mu \mathrm{M}$, respectively (Figure 4C). These data demonstrated a strong remyelinating efficacy of TF in live animals.

\section{In Mice}

Following LPC-induced demyelination in the dorsal funiculus (Figure 5, A and B), TF $(20 \mathrm{mg} / \mathrm{kg}$ ) was administrated through oral gavage daily, for 10 days, starting 1 day after LPC injection.

The number of oligodendroglial lineage cells and postmitotic oligodendrocytes was quantified using Olig2 (Figure 5, C, D, $\mathrm{I}$, and $\mathrm{J}$ ) and $\mathrm{APC}(\mathrm{CC} 1 \mathrm{mAb})$ (Figure 5, F-J) as markers, respectively. The number of Olig $2^{+}$oligodendrocyte lineage cells within the lesion did not change between the groups (Figure 5, E). By contrast, TF increased the number of CC1 postmitotic oligodendrocytes in the lesion compared with animals treated with the vehicle $(241.2 \pm 19.8$ vs $179.8 \pm 20.9$; 
Figure 3 OPC Differentiation Induced by Teriflunomide Is Reversed by Ro 48-8071 and Associated With 8,9-Unsaturated Sterol Production
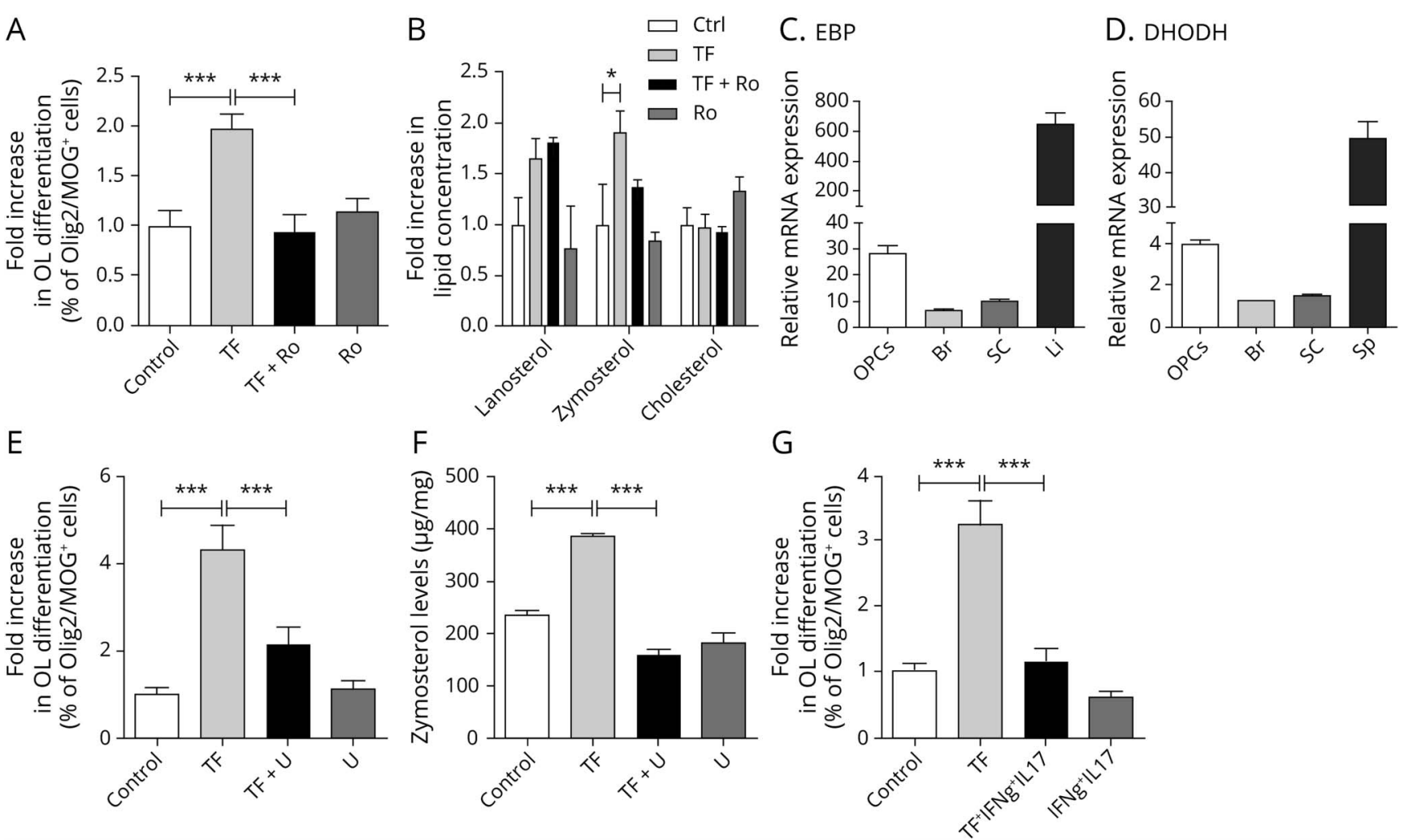

(A) OPCs treated with unconditioned (Ctrl) or TF and/or Ro 48-8071 were immunostained against Olig2 and MOG at 96 hours following treatment. The percentage of Olig2 ${ }^{+}$cells coexpressing MOG was significantly increased in cultures treated with TF compared with control, an effect blocked by the Ro $48-8071$ treatment. (B) Quantitation of sterol levels in OPCs treated with TF and/or Ro 48-8071. In OPC cultures treated for 24 hours with TF, the level of zymosterol was increased (results are expressed as \% of controls), whereas lanosterol and cholesterol levels were unchanged. (C and D) EBP and DHODH messenger RNA levels measured by reverse transcriptase-quantitative polymerase chain reaction in OPCs, Br, and SC. The Li and Sp were used as positive control for EBP and DHODH enzymatic gene expression, respectively. Glyceraldehyde 3-phosphate dehydrogenase was used as the reference gene. (E) The percentage of MOG $^{+} / \mathrm{Olig}^{+}{ }^{+}$oligodendrocytes at 96 hours was significantly increased in OPCs treated with TF compared with control, an effect reversed by the uridine treatment. (F) Uridine blocked the accumulation of zymosterol induced by teriflunomide. (G) The percentage of $\mathrm{MOG}^{+} / \mathrm{Olig}^{+}$oligodendrocytes at 96 hours following treatment with TF and/or IFNy/IL-17 was significantly decreased in OPCs treated with TF and exposed to IFNy/IL-17 cytokines compared with TF. Data are shown as mean \pm SEM from 3 individual experiments. ${ }^{*} p<0.05 ;{ }^{* *} p<0.001$ (1-way ANOVA, Newman-Keuls post hoc test). Br = brain; $\mathrm{DHODH}=$ dihydroorotate dehydrogenase; EBP = emopamil binding protein; $\mathrm{Li}=$ liver; $\mathrm{OPC}=$ oligodendrocyte precursor cell; $\mathrm{SC}=$ spinal cord; $\mathrm{Sp}=$ spleen; TF = teriflunomide.

Figure 5, H). Importantly, the fraction of Olig2 ${ }^{+}$cells also positive for CC1 was significantly increased in the lesion of TF-treated mice $(48.9 \% \pm 3.1 \%)$ compared with controls $(28.7 \% \pm 2.5 \%)$ (Figure $5 \mathrm{~K})$. These findings demonstrated that $\mathrm{TF}$ promotes oligodendrocyte differentiation in vivo during remyelination following LPC-induced demyelination.

We then investigated whether TF treatment modulated myelin repair in the LPC induced focal mouse model of demyelination. In control animals, remyelinating axons were characterized by thin myelin sheaths compared with TF-treated animals (Figure 6, A and B). At 11 days post-lesion, quantification revealed $67.6 \% \pm 3.5 \%$ of remyelinated axons in TF-treated animals compared with $56.2 \% \pm 2.6 \%$ in control animals.

\section{Discussion}

We report here that $\mathrm{TF}$, an immune active drug approved for the treatment of relapsing MS, enhanced oligodendroglial differentiation in vitro at nanomolar concentrations, both on neonatal and adult purified OPCs in cultures, an effect mediated by an accumulation of 8,9-unsaturated sterols. We further showed that following a systemic administration, TF promoted remyelination in vivo across species in 2 noninflammatory models of demyelination. These results highlight a potential bystander effect of the drug, independent from its action on the immune system.

The classical mechanism of action of TF in MS is a reversible inhibition of dihydroorotate dehydrogenase (DHODH), a mitochondrial enzyme involved in the de novo pyrimidine synthesis pathway. This enzyme is highly expressed in proliferating lymphocytes, and its inhibition in the periphery results in a reduced proliferation of activated lymphocytes, impeding the availability of activated autoreactive immune cells to infiltrate the CNS. ${ }^{11}$ Through its action on DHODH, $\mathrm{TF}$ targets both $\mathrm{T}$ - and B-cell activation ${ }^{28} \mathrm{TF}$ was also described to enhance, in humans, the expression of programmed 

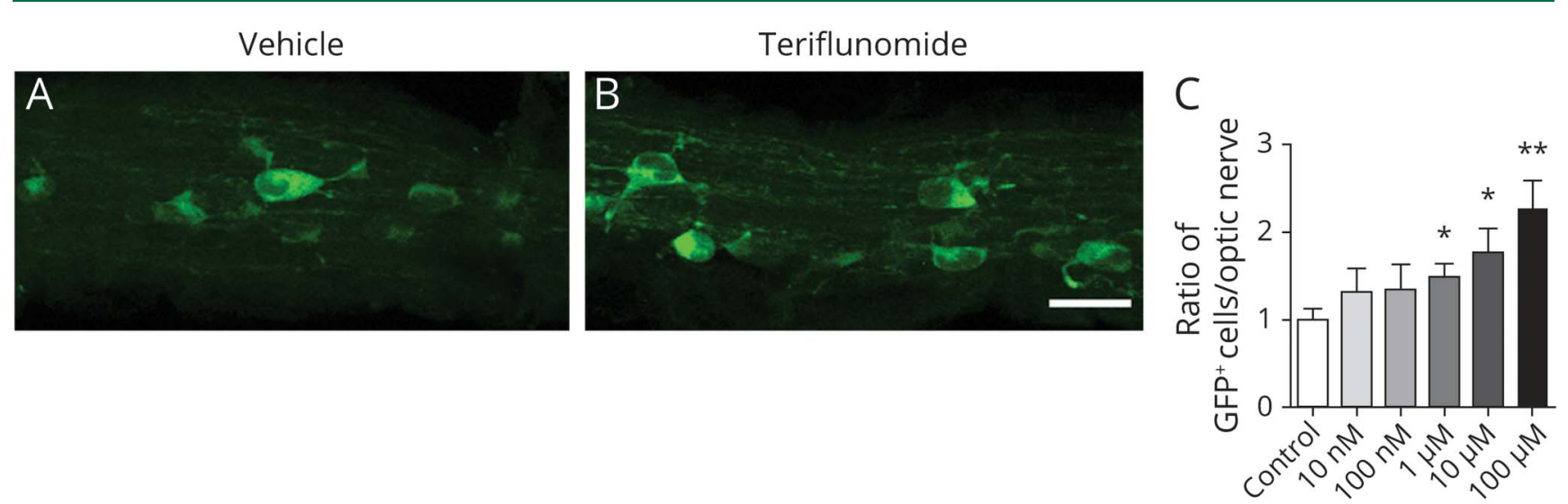

Dose response of remyelination potency of TF. (A and B) Detection of GFP ${ }^{+}$oligodendroglial cells in optic nerves of stage53 Mbp:GFP-NTR tadpoles. Demyelination of stage53 Mbp:GFP-NTR tadpoles was achieved by 10 days exposure to metronidazole $(10 \mathrm{mM})$ in the swimming water. Tadpoles were then returned to normal water (control) or TF for 3 days. The number of GFP' cells in the optic nerve in control (A) is lower compared with TF-treated tadpoles (B). (C) Remyelination was assayed by counting the number of $\mathrm{GFP}^{+}$cells per optic nerve on day 3 of the repair period. Treatment of tadpoles with TF at concentrations ranging between $1 \mu \mathrm{M}$ and $100 \mu \mathrm{M}$ improved remyelination up to 2.25-fold compared with spontaneous recovery (control) set as 1 . Data shown are mean \pm SEM, $n=5$-8 tadpoles per group. ${ }^{*} p<0.05 ;{ }^{*} p<0.01$ (1-way ANOVA, Dunn post hoc test. Scale bar in A and B $=20 \mu \mathrm{m}$. MBP-GFP-NTR $=$ myelin basic protein-GFP-nitroreductase; TF = teriflunomide.

death-ligand 1 by monocytes, contributing to a tolerogenic bias in the blood of patients with MS. ${ }^{29}$ In a chronic genetic dysmyelinating model, TF was also shown to foster the proliferation of $\mathrm{CD} 8^{+} \mathrm{CD} 122^{+} \mathrm{PD}-1^{+}$regulatory $\mathrm{T}$ cells in the CNS resulting in neuronal protection. ${ }^{30}$

Beyond its effect on the adaptive immune system, only a few bystander effects have been suggested to date. In vitro, high concentration $(5 \mu \mathrm{M})$ slightly reduced microglial proliferation in mixed glial cultures derived from rats, but did not affect microglial differentiation status. ${ }^{31}$ In vivo, oral gavage with TF in mice chronically infected by the Theiler virus resulted in a nonsignificant reduction in microglial density in the corpus callosum. ${ }^{32}$ Leflunomide, a prodrug of TF, could mitigate experimental autoimmune encephalitis, partly by acting on microglial cells independently of pyrimidine depletion. ${ }^{33}$ In rat glial cultures, TF was also shown to promote the differentiation of OPCs toward mature oligodendrocytes, but only when short ( 1 day) and early pulses at high concentration $(5 \mu \mathrm{M})$ were added to the medium. ${ }^{12}$ When the treatment was prolonged for several days, the effect on differentiation and myelination disappeared. Blood concentration of unbound TF in treated patients is usually within the submicromolar range, ${ }^{34}$ and at best reach $2-4 \mu \mathrm{M},{ }^{35}$ making unlikely that higher concentration could be reached in MS lesion and precluding any promyelinating effect behind a preserved blood brain barrier (BBB). We therefore investigated whether lower concentration of the drug in cultures could also affect oligodendrocytes and questioned about a remyelinating efficacy in vivo in demyelination models with an intact BBB. We showed that very low-concentration, down to $10 \mathrm{nM}$, TF decreased OPC proliferation and enhanced oligodendrocyte differentiation, without the need to apply short pulses. Of note, this effect was shown not only for OPCs derived from newborn animals but also on OPCs purified from adult brains, which are the key actors of the remyelinating process that should be targeted by a therapeutic promyelinating agent. ${ }^{36}$ As $1 \%-2 \%$ of the serum concentration of TF has been shown to cross the $\mathrm{BBB},{ }^{12}$ it is reasonable to hypothesize that in humans, a $10 \mathrm{nM}$ concentration may reach the brain without any BBB leakage and could, in theory, act on adult OPCs to promote repair. Our in vivo results further support a repair capacity across species in 2 noninflammatory models with no BBB pathology. In each model, TF significantly enhanced the differentiation of newly formed oligodendrocytes, and this finally resulted in an increased formation of new myelin sheets characterized by a thinner diameter on electronic microscopy. We provided here in vivo evidence of a regenerative property of TF in rodents.

A key finding of our study was the identification of the 8,9unsaturated sterol pathway as a potential mechanism involved in the promyelinating effect of TF. Those intermediate metabolites in the cholesterol synthesis cascade have been identified as able to promote the formation of new mature oligodendrocytes and their accumulation was proposed as a shared mechanism by many small molecule enhancers of remyelination independently of their canonical target. ${ }^{9}$ Inhibition of a narrow range of cholesterol biosynthesis enzymes between CYP51 (a target of imidazole antifungal drugs) and EBP, a potential target for the promyelinating drugs clemastine, tamoxifen, and bazedoxifene, ${ }^{9,37}$ has therefore emerged as a promising pharmacologic pathway for remyelinating strategies. Inhibition with Ro 48-8071 of the oxidosqualene cyclase, an enzyme that catalyzes the step just before the synthesis of lanosterol, the first 8,9-unsaturated sterol, reverted the oligodendroglial differentiation induced by TF in culture, demonstrating the involvement of this cascade. 

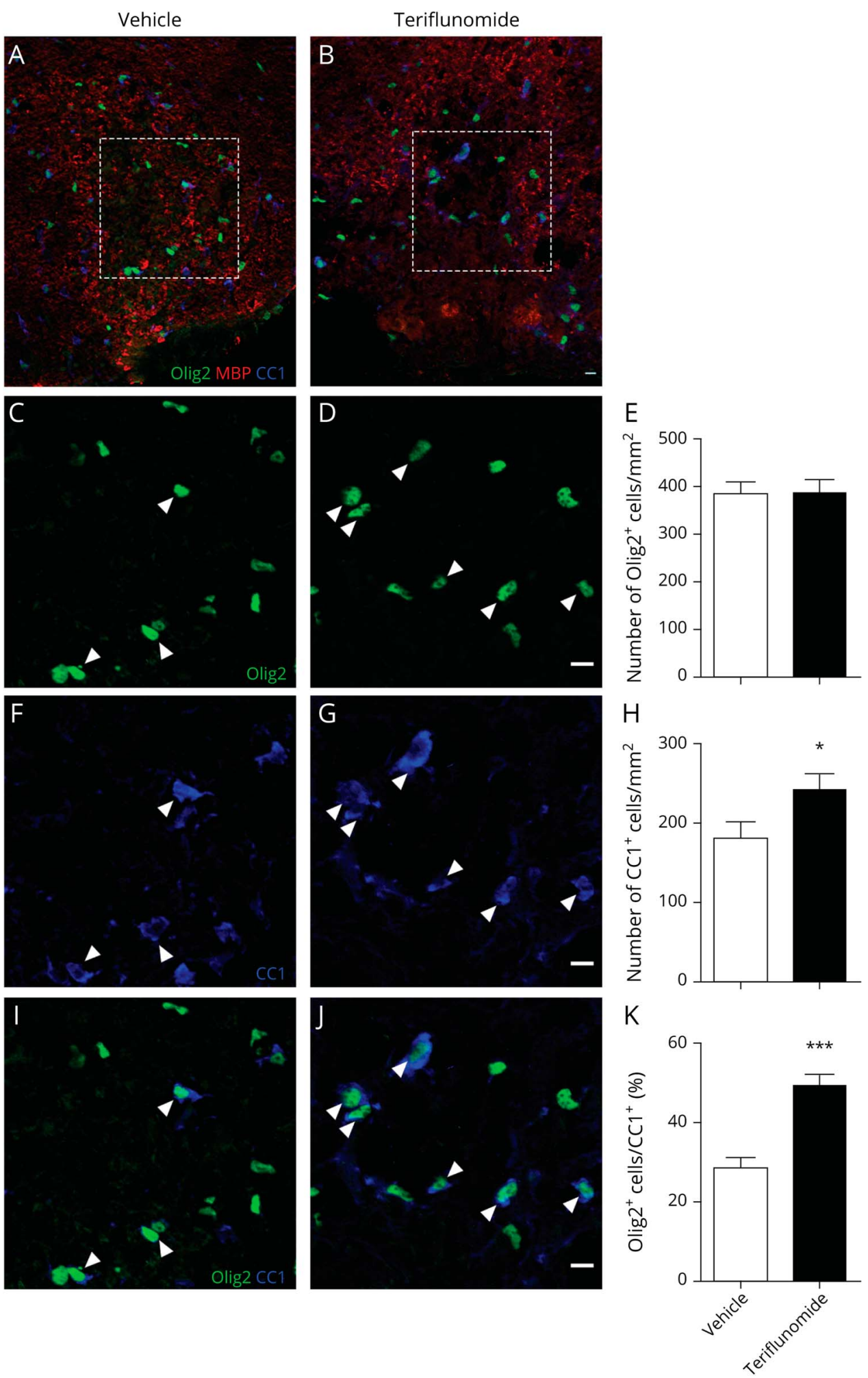

Demyelination was induced by lysophosphatidylcholine on day 0 , and differentiation was assessed on day 11. (A and B) Triple immunolabeling for Olig2, MBP, and CC1 in the spinal cord lesion of control ( $\mathrm{NaCl})$-treated mice (A) and TF-treated mice (B). The lesion limits are indicated by white dashed lines. (C and D) Immunolabeling for Olig2 in the core of the lesion of control ( $\mathrm{NaCl}$ )-treated mice (C) and TF-treated mice (D). (E) No difference in the number of Olig2 ${ }^{+}$cells $/ \mathrm{mm}^{2}$ is observed between the groups. ( $\mathrm{F}$ and G) Immunolabeling for CC1 in the core of the lesion of control $(\mathrm{NaCl})$ treated mice $(\mathrm{F})$ and TF-treated mice (G). (H) Significantly, more $\mathrm{CC}^{+}{ }^{+}$cells are present in the lesion of TF-treated mice compared with control. (I and J) Merge showing the colabeling for Olig2 and CC1. White arrowheads indicate cells coexpressing Olig2 and CC1. (K) The percentage of Olig2 ${ }^{+}$ cells coexpressing CC1 is significantly increased in the lesion of TF treated mice compared with control. Data shown are mean \pm SEM, $n=5$ mice per group. ${ }^{*} p<0.05 ; * \star \star x p<0.001$ (Student 2-tailed unpaired $t$ test). Scale bar $=10 \mu \mathrm{m}$. MBP = myelin basic protein; TF = teriflunomide.

Furthermore, we showed that TF significantly enhanced the accumulation of zymosterol, which has been identified as the most potent sterol in oligodendroglial differentiation assays. ${ }^{9}$ We therefore hypothetized that TF could inhibit EBP, the enzyme catalyzing zymosterol in the cholesterol biosynthesis pathway. We found that OPCs indeed express moderate levels of messenger RNAs for EBP, but subsequently failed to show a direct effect of TF on EBP. Conversely, oligodendrocyte 

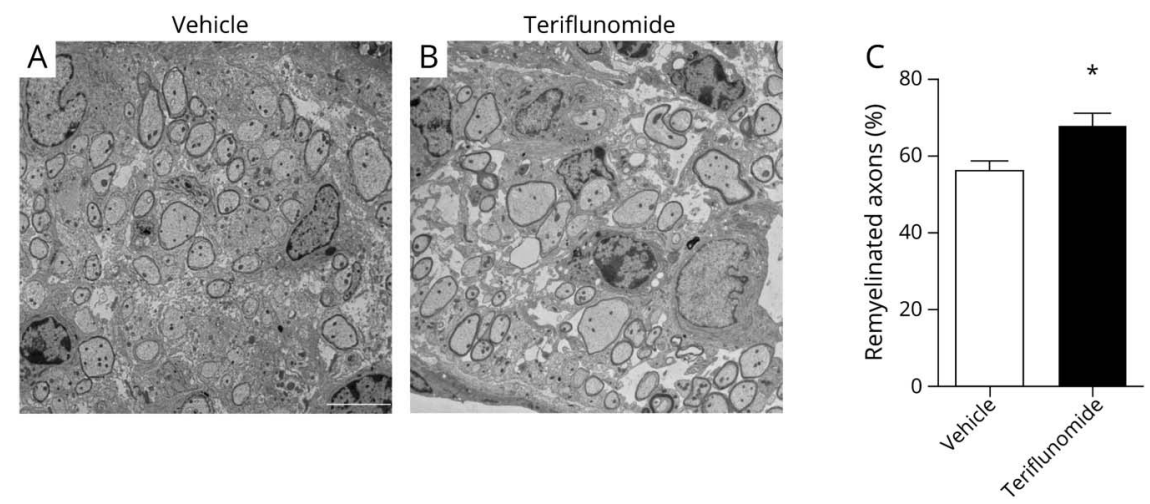

(A and B) Electron micrographs of the lesion area at 11 days postlesion. In control-treated mice (A) and in TF-treated mice (B). The proportion of remyelinated axons was increased in TF-treated mice. (C) The percentage of remyelinated axons is significantly increased in the lesion of TF-treated mice compared with controls. Data shown are mean \pm SEM, $n=5$ mice. ${ }^{*} p<0.05$ (Student 2 tailed unpaired $t$ test). Scale bars $=5 \mu \mathrm{m}$. TF $=$ teriflunomide.

differentiation and zymosterol accumulation induced by TF were both abrogated in the presence of an excess of uridine, suggesting an involvement of the DHODH canonical pathway. ${ }^{38}$ Whether inhibiting DHODH in oligodendrocyte could result in an indirect effect on cholesterol biogenesis cascade is a burning question that should be addressed in further research.

One limitation of our study is that it focused on noninflammatory animal models, questioning about its relevance in the human context. MS is an inflammatory demyelinating disease in which immune cells could inhibit oligodendroglial differentiation and remyelination. ${ }^{39}$ It was reported that the blocked oligodendroglial differentiation induced by proinflammatory cytokines was not restored by the application of oligodendroglial differentiation promoting drugs. ${ }^{40}$ According to this, we found that the direct effect of TF on oligodendrocyte was not maintained in the presence of interleukin-17 and interferon- $\gamma$. However, adding TF to peripheral blood mononuclear cells was also shown to rescue oligodendroglial differentiation, ${ }^{40}$ attesting that the dual effect of this drug, on inflammatory and remyelination cells, could indeed favor regeneration in the human context. In clinical phase 3 trials, TF reduced the annualized relapse rate in relapsing MS (around $30 \%$ reduction compared with placebo, ${ }^{10,41}$ ) and clinically isolated syndrome. ${ }^{42}$ However, despite this moderate effect on relapses, TF consistently improved several outcomes linked to persistent tissue damage such as relapses with sequelae, ${ }^{42}$ brain atrophy, ${ }^{43}$ and hypointense lesions on MRI. ${ }^{10}$ It also significantly reduced disability progression in the 2 placebo-controlled phase 3 studies in relapsing MS. ${ }^{10,41}$ Although not demonstrating a regenerative or neuroprotective effect of the drug, these results have raised the possibility of a protective action beyond immunomodulation. How the impact on remyelination could be explored in clinical trials is a tricky question, as it would imply to differentiate the antiinflammatory and the remyelinating properties. A reanalysis of previously acquired imaging data from pivotal trials focusing on markers more sensitive to myelin content such as $\mathrm{T} 1 / \mathrm{T} 2$ ratios $^{44,45}$ or more advanced quantitative sequences when avail$\mathrm{able}^{46}$ would be of great added value to achieve this goal. An alternative would be to design novel and focused trials aiming at investigating remyelination using the most specific tools available, for instance electrophysiology, ${ }^{47}$ quantitative $\mathrm{MRI},{ }^{46}$ or positron emission tomography. ${ }^{7}$

In conclusion, we have shown that TF decreases OPC proliferation, induces OPC differentiation, and promotes remyelination in living animals. Importantly, our study provides a novel mechanism of action of TF on remyelination in vivo through the accumulation of 8,9-unsaturated sterols, a crucial cellular mechanism involved in oligodendrocyte physiology. These findings reinforce the idea that modulation of the cholesterol biosynthesis pathway represents a promising therapeutic target for the development of remyelinating strategies and open the perspective of an additional benefit of TF treatment for patients with MS.

\section{Acknowledgment}

The authors thank Dr. P. Soriano for providing PDGFaR::GFP transgenic mice. They warmly thank Anna Revellat for precious help and fruitful discussion. They thank Guoqing Sheng from Sanofi for providing the screening assay for EBP and for testing teriflunomide on it. They thank C. Blanc and B. Hoareau (Flow Cytometry Core CyPS, Sorbonne Université, Pitié-Salpêtrière Hospital, Paris, France) for their assistance on FACS. The study was performed at the cell culture (Celis), histology (Histomics) and preclinical functional exploration platforms (PHENOICMice and Xenopus core facility) of ICM. The authors thank all the technical staff members involved in these experiments.

\section{Study Funding}

This work was supported by an unrestricted grant from Genzyme-Sanofi. Our laboratory was also supported by the program "Investissements d'avenir" program ANR-10-IAIHU06 (IHU-A-ICM), INSERM, CNRS, and Sorbonne Université.

\section{Disclosure}

E. Martin, M.-S. Aigrot, and C. Bachelin report no disclosures relevant to the manuscript. F. Lamari reports personal fees from Amicus Pharmaceutical and travel support from SanofiGenzyme. C. Lubetzki reports grants and personal fees from Biogen and personal fees from Merck Serono, Roche, Rewind, 
and Ipsen. B.N. Oumesmar reports grants and personal fees from UCB Pharma and grants from Genentech. B. Zalc reports grants from Novartis and Merck. B. Stankoff reports grants and personal fees from Roche, Genzyme, and Merck Serono and personal fees from Novartis, Teva, and Biogen. Go to Neurology.org/NN for full disclosures.

\section{Publication History}

Received by Neurology: Neuroimmunology \& Neuroinflammation November 9, 2020. Accepted in final form August 23, 2021.

\section{Appendix Authors}

\begin{tabular}{lll}
\hline Name & Location & Contribution \\
\hline $\begin{array}{ll}\text { Elodie Martin, } \\
\text { PhD }\end{array}$ & $\begin{array}{l}\text { Paris Brain Institute, } \\
\text { Paris, France }\end{array}$ & $\begin{array}{l}\text { Designed and conceptualized the } \\
\text { study; major role in the acquisition } \\
\text { of data; analyzed the data; } \\
\text { interpreted the data; and drafted } \\
\text { the manuscript for intellectual } \\
\text { content }\end{array}$ \\
&
\end{tabular}

\begin{tabular}{|c|c|c|}
\hline $\begin{array}{l}\text { Marie- } \\
\text { Stephane } \\
\text { Aigrot, PhD }\end{array}$ & $\begin{array}{l}\text { Paris Brain Institute, } \\
\text { Paris, France }\end{array}$ & $\begin{array}{l}\text { Major role in the acquisition of data; } \\
\text { analyzed the data; interpreted the } \\
\text { data; and drafted the manuscript } \\
\text { for intellectual content }\end{array}$ \\
\hline $\begin{array}{l}\text { Foudil } \\
\text { Lamari, MD, } \\
\text { PhD }\end{array}$ & $\begin{array}{l}\text { Sorbonne University } \\
\text { Hospital, Paris, } \\
\text { France }\end{array}$ & $\begin{array}{l}\text { Acquisition of data (sterol } \\
\text { quantification) }\end{array}$ \\
\hline $\begin{array}{l}\text { Corinne } \\
\text { Bachelin, PhD }\end{array}$ & $\begin{array}{l}\text { Paris Brain Institute, } \\
\text { Paris, France }\end{array}$ & $\begin{array}{l}\text { Acquisition of data (electronic } \\
\text { microscopy) }\end{array}$ \\
\hline $\begin{array}{l}\text { Catherine } \\
\text { Lubetzki, MD, } \\
\text { PhD }\end{array}$ & $\begin{array}{l}\text { Paris Brain Institute, } \\
\text { Paris, France }\end{array}$ & $\begin{array}{l}\text { Designed and conceptualized the } \\
\text { study and drafted the manuscript } \\
\text { for intellectual content }\end{array}$ \\
\hline $\begin{array}{l}\text { Brahim Nait } \\
\text { Oumesmar, } \\
\text { PhD }\end{array}$ & $\begin{array}{l}\text { Paris Brain Institute, } \\
\text { Paris, France }\end{array}$ & $\begin{array}{l}\text { Acquisition of data (electronic } \\
\text { microscopy) }\end{array}$ \\
\hline $\begin{array}{l}\text { Bernard Zalc, } \\
\text { MD, PhD }\end{array}$ & $\begin{array}{l}\text { Paris Brain Institute, } \\
\text { Paris, France }\end{array}$ & $\begin{array}{l}\text { Acquisition of data (tadpole } \\
\text { experiment) and drafted the } \\
\text { manuscript for intellectual content }\end{array}$ \\
\hline $\begin{array}{l}\text { Bruno } \\
\text { Stankoff, MD, } \\
\text { PhD }\end{array}$ & $\begin{array}{l}\text { Paris Brain Institute, } \\
\text { Paris, France }\end{array}$ & $\begin{array}{l}\text { Obtained funding for the study; } \\
\text { designed and conceptualized the } \\
\text { study; acquisition and } \\
\text { interpretation of data; and drafted } \\
\text { the manuscript for intellectual } \\
\text { content }\end{array}$ \\
\hline
\end{tabular}

\section{References}

1. Criste G, Trapp B, Dutta R. Axonal loss in multiple sclerosis; causes and mechanisms. Handb Clin Neurol. 2014;122:101-113.

2. Lubetzki C, Stankoff B. Demyelination in multiple sclerosis. Handb Clin Neurol. 2014; 122:89-99.

3. Irvine KA, Blakemore WF. Remyelination protects axons from demyelinationassociated axon degeneration. Brain. 2008;131(pt 6):1464-1477.

4. Mei F, Lehmann-Horn K, Shen YA, et al. Accelerated remyelination during inflammatory demyelination prevents axonal loss and improves functional recovery. Elife. 2016 Sep 27;5:e18246

5. Périer O, Grégoire A. Electron microscopic features of multiple sclerosis lesions. Brain. 1965;88(5):937-952.

6. Prineas JW, Barnard RO, Kwon EE, Sharer LR, Cho E-S. Multiple sclerosis: remyelination of nascent lesions: remyelination of nascent lesions. Ann Neurol. 1993;33(2):137-151.

7. Bodini B, Veronese M, García-Lorenzo D, et al. Dynamic imaging of individual remyelination profiles in multiple sclerosis. Ann Neurol. 2016;79(5):726-738.

8. Lubetzki C, Zalc B, Williams A, Stadelmann C, Stankoff B. Remyelination in multiple sclerosis: from basic science to clinical translation. Lancet Neurol. 2020;19(8):678-688.

9. Hubler Z, Allimuthu D, Bederman I, et al. Accumulation of 8,9-unsaturated sterols drives oligodendrocyte formation and remyelination. Nature. 2018;560(7718):372-376.
10. O'Connor P, Wolinsky JS, Confavreux C, et al. Randomized trial of oral teriflunomide for relapsing multiple sclerosis. N Engl J Med. 2011;365(14):1293-1303.

11. Bar-Or A, Pachner A, Menguy-Vacheron F, Kaplan J, Wiendl H. Teriflunomide and its mechanism of action in multiple sclerosis. Drugs. 2014;74(6):659-674.

12. Göttle P, Manousi A, Kremer D, Reiche L, Hartung HP, Küry P. Teriflunomide promotes oligodendroglial differentiation and myelination. J Neuroinflammation. 2018;15(1):76.

13. Klinghoffer RA, Mueting-Nelsen PF, Faerman A, Shani M, Soriano P. The two PDGF receptors maintain conserved signaling in vivo despite divergent embryological functions. Mol Cell. 2001;7(2):343-354.

14. Stankoff B, Demerens C, Goujet-Zalc C, et al. Transcription of myelin basic protein promoted by regulatory elements in the proximal 5' sequence requires myelinogenesis. Mult Scler. 1996;2(3):125-132.

15. Kaya F, Mannioui A, Chesneau A, et al. Live imaging of targeted cell ablation in Xenopus: a new model to study demyelination and repair. J Neurosci. 2012;32(37):12885-12895.

16. Nieuwkoop PD, Faber J. Normal Table of Xenopus laevis. Garland; 1994.

17. Lubetzki C, Goujet-Zalc C, Gansmüller A, Monge M, Brillat A, Zalc B. Morphological, biochemical, and functional characterization of bulk isolated glial progenitor cells. J Neurochem. 1991;56(2):671-680.

18. Piaton G, Aigrot MS, Williams A, et al. Class 3 semaphorins influence oligodendrocyte precursor recruitment and remyelination in adult central nervous system. Brain. 2011; 134(Pt 4):1156-1167.

19. Klinghoffer RA, Hamilton TG, Hoch R, Soriano P. An allelic series at the PDGF $\alpha$ R locus indicates unequal contributions of distinct signaling pathways during development. Dev Cell. 2002;2(1):103-113.

20. Stankoff B, Barron S, Allard J, et al. Oligodendroglial expression of edg-2 receptor: developmental analysis and pharmacological responses to lysophosphatidic acid. Mol Cell Neurosci. 2002;20(3):415-428

21. Honda A, Yamashita K, Miyazaki H, et al. Highly sensitive analysis of sterol profiles in human serum by LC-ESI-MS/MS. J Lipid Res. 2008;49(9):2063-2073.

22. Hanin A, Baudin P, Demeret S, et al. Disturbances of brain cholesterol metabolism: a new excitotoxic process associated with status epilepticus. Neurobiol Dis. 2021;154:105346.

23. Tepavčević V, Kerninon C, Aigrot MS, et al. Early netrin-1 expression impairs central nervous system remyelination. Ann Neurol. 2014;76(2):252-268.

24. Mannioui A, Vauzanges Q Fini JB, et al. The Xenopus tadpole: an in vivo model to screen drugs favoring remyelination. Mult Scler. 2018;24(11):1421-1432.

25. Scolding NJ, Frith S, Linington C, Morgan BP, Campbell AK, Compston DA. Myelinoligodendrocyte glycoprotein (MOG) is a surface marker of oligodendrocyte maturation. J Neuroimmunol. 1989;22(3):169-176.

26. Solly SK, Thomas JL, Monge M, et al. Myelin/oligodendrocyte glycoprotein (MOG) expression is associated with myelin deposition. Glia. 1996;18(1):39-48.

27. Kirby L, Jin J, Cardona JG, et al. Oligodendrocyte precursor cells present antigen and are cytotoxic targets in inflammatory demyelination. Nat Commun. 2019;10(1):3887.

28. Gandoglia I, Ivaldi F, Laroni A, et al. Teriflunomide treatment reduces B cells in patients with MS. Neurol Neuroimmunol Neuroinflamm. 2017;4(6):e403.

29. Medina S, Sainz de la Maza S, Villarrubia N, et al. Teriflunomide induces a tolerogenic bias in blood immune cells of MS patients. Ann Clin Transl Neurol. 2019;6(2):355-363.

30. Groh J, Hörner M, Martini R. Teriflunomide attenuates neuroinflammation-related neural damage in mice carrying human PLP1 mutations. J Neuroinflammation. 2018; 15(1): 194 .

31. Wostradowski T, Prajeeth CK, Gudi V, et al. In vitro evaluation of physiologically relevant concentrations of teriflunomide on activation and proliferation of primary rodent microglia. J Neuroinflammation. 2016;13(1):250.

32. Pol S, Sveinsson M, Sudyn M, et al. Teriflunomide's effect on glia in experimental demyelinating disease: a neuroimaging and histologic study. J Neuroimaging. 2019;29(1):52-61.

33. Korn T, Magnus T, Toyka K, Jung S. Modulation of effector cell functions in experimental autoimmune encephalomyelitis by leflunomide-mechanisms independent of pyrimidine depletion. J Leukoc Biol. 2004;76(5):950-960.

34. Hopkins AM, Moghaddami M, Foster DJR, Proudman SM, Upton RN, Wiese MD. Intracellular $\mathrm{CD} 3+\mathrm{T}$ lymphocyte teriflunomide concentration is poorly correlated with and has greater variability than unbound plasma teriflunomide concentration. Drug Metab Dispos. 2017;45:8-16.

35. Miller AE. Oral teriflunomide in the treatment of relapsing forms of multiple sclerosis: clinical evidence and long-term experience. Ther Adv Neurol Disord. 2017;10(12):381-396.

36. Foerster S, Hill MFE, Franklin RJM. Diversity in the oligodendrocyte lineage: plasticity or heterogeneity? Glia. 2019;67(10):1797-1805.

37. Rankin KA, Mei F, Kim K, et al. Selective estrogen receptor modulators enhance CNS remyelination independent of estrogen receptors. J Neurosci. 2019;39(12):2184-2194.

38. Li L, Liu J, Delohery T, Zhang D, Arendt C, Jones C. The effects of teriflunomide on lymphocyte subpopulations in human peripheral blood mononuclear cells in vitro. J Neuroimmunol. 2013;265(1-2):82-90.

39. $\mathrm{HeB} \mathrm{K}$, Starost L, Kieran NW, et al. Lesion stage-dependent causes for impaired remyelination in MS. Acta Neuropathol. 2020;140(3):359-375.

40. Starost L, Lindner M, Herold M, et al. Extrinsic immune cell-derived, but not intrinsic oligodendroglial factors contribute to oligodendroglial differentiation block in multiple sclerosis. Acta Neuropathol. 2020;140(5):715-736.

41. Confavreux C, O'Connor P, Comi G, et al. Oral teriflunomide for patients with relapsing multiple sclerosis (TOWER): a randomised, double-blind, placebocontrolled, phase 3 trial. Lancet Neurol. 2014;13(3):247-256.

42. Miller AE, Macdonell R, Comi G, et al. Teriflunomide reduces relapses with sequelae and relapses leading to hospitalizations: results from the TOWER study. J Neurol. 2014;261(9):1781-1788.

43. Radue E-W, Sprenger T, Gaetano L, et al. Teriflunomide slows BVL in relapsing MS Neurol Neuroimmunol Neuroinflamm. 2017;4(5):e390. 
44. Hagiwara A, Hori M, Kamagata K, et al. Myelin measurement: comparison between simultaneous tissue relaxometry, magnetization transfer saturation index, and tlw/ t2w ratio methods. Sci Rep. 2018;8(1):10554.

45. Nakamura K, Chen JT, Ontaneda D, Fox RJ, Trapp BD. T1-/T2-weighted ratio differs in demyelinated cortex in multiple sclerosis. Ann Neurol. 2017;82(4):635-639.
46. Mallik S, Samson RS, Wheeler-Kingshott CA, Miller DH. Imaging outcomes for trials of remyelination in multiple sclerosis. J Neurol Neurosurg Psychiatry. 2014;85(12): 1396-1404.

47. Heidari M, Radcliff $\mathrm{AB}, \mathrm{McLellan}$ GJ, et al. Evoked potentials as a biomarker of remyelination. Proc Natl Acad Sci USA. 2019;116(52):27074-27083. 


\section{Neurology \\ Neuroimmunology \& Neuroinflammation}

\section{Teriflunomide Promotes Oligodendroglial 8,9-Unsaturated Sterol Accumulation and CNS Remyelination \\ Elodie Martin, Marie-Stephane Aigrot, Foudil Lamari, et al. \\ Neurol Neuroimmunol Neuroinflamm 2021;8; \\ DOI 10.1212/NXI.0000000000001091}

This information is current as of October 12, 2021

Updated Information \&

Services

References

Subspecialty Collections

Permissions \& Licensing

Reprints including high resolution figures, can be found at:

http://nn.neurology.org/content/8/6/e1091.full.html

This article cites 46 articles, 8 of which you can access for free at: http://nn.neurology.org/content/8/6/e1091.full.html\#\#ref-list-1

This article, along with others on similar topics, appears in the following collection(s):

Multiple sclerosis

http://nn.neurology.org//cgi/collection/multiple_sclerosis

Information about reproducing this article in parts (figures,tables) or in its entirety can be found online at:

http://nn.neurology.org/misc/about.xhtml\#permissions

Information about ordering reprints can be found online: http://nn.neurology.org/misc/addir.xhtml\#reprintsus

Neurol Neuroimmunol Neuroinflamm is an official journal of the American Academy of Neurology.

Published since April 2014, it is an open-access, online-only, continuous publication journal. Copyright

Copyright (C) 2021 The Author(s). Published by Wolters Kluwer Health, Inc. on behalf of the American

Academy of Neurology.. All rights reserved. Online ISSN: 2332-7812.

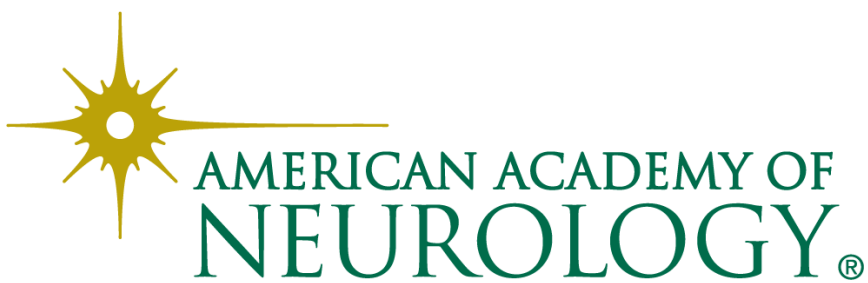

